\title{
Hydrological response of a headwater catchment in southeastern Brazil Part II: Estimate of evapotranspiration with micrometeorological and water budget methods
}

\author{
Mariane Chittolina ${ }^{1}$, Rodolfo Souza ${ }^{2}$, Evandro Moimaz Anselmo ${ }^{3}$, and Humberto Rocha ${ }^{1}$ \\ ${ }^{1}$ Universidade de Sao Paulo Instituto de Energia e Ambiente \\ ${ }^{2}$ Texas A\&M University \\ ${ }^{3}$ Fundação Cearense de Meteorologia e Recursos Hídricos (Funceme) Rui Barbosa Evenue \\ 1246 CEP 60115221 Aldeota Fortaleza CE Brazil
}

March 1, 2022

\begin{abstract}
We estimated the seasonal patterns of evapotranspiration (ET) using measured field data in a typical headwater basin and four sub-basins, in subtropical climate region of Serra da Mantiqueira/South-East Brazil, with a multi-instrument hydrometeorological set (standard weather station variables, discharge, soil moisture, and surface-atmosphere turbulent fluxes), towards providing regional data, to our knowledge, hitherto non-existent, of independent ET from micrometeorological methods (eddy covariance EC and Bowen ratio BR), energy balance closure corrections, and water budget based modelling, to discuss the magnitude and seasonality of the most accurate ET possible to be obtained. We had an unsatisfactory closure of the energy balance for the EC method, and the BR method likely also did not meet satisfactory estimates, as both suffered from the non-ideal conditions of the experimental site imposed by secondary atmospheric circulations. The comparison of the mean annual ET among 3 correction methods with the water budget showed an agreement in the range from 2.6 to $2.9 \mathrm{~mm}^{-1}$, that was particularly met by the approaches of Mauder et al. (2013) and Twine et al. (2001), of $2.8 \mathrm{~mm} \mathrm{~d}^{-1}$. These corrections respected upper limits of potential evapotranspiration. Nighttime corrections were not applied, that possibly explains how daily totals of the $\mathrm{H}+$ LE sum overestimated about $9 \%$ of the available energy, that led to an overestimated ET of roughly less than $5 \%$ by those corrections. The seasonal variability of ET ranged from the minimum of $1.3 \mathrm{~mm}$ d- 1 in July, and high fluxes in the wet season of about $3.5 \mathrm{~mm} \mathrm{~d}-1$. The maximum $\mathrm{H}$ flux in September indicated how the onset of rainfall and the quick response of soil moisture recovery prevented $\mathrm{H}$ to increase onwards on the rhythm of radiation. Soil moisture appeared to play a key role in not only ET but in controlling the energy partition.
\end{abstract}

\section{Hydrological response of a headwater catchment in southeastern Brazil}

Part II: Estimate of evapotranspiration with micrometeorological and water budget methods Mariane Chittolina ${ }^{1,2}$, Rodolfo Marcondes Silva Souza ${ }^{3}$, Evandro Moimaz Anselmo ${ }^{4}$ \& Humberto Ribeiro da Rocha ${ }^{1,2}$

${ }^{1}$ Institute of Energy and Environment, University of Sao Paulo (IEE-USP), Brazil, Professor Luciano Gualberto Avenue, 128, CEP 05508-010, University City - São Paulo - SP

${ }^{2}$ Institute of Astronomy, Geophysics and Atmospheric Sciences, Department of Atmospheric Science, University of Sao Paulo (IAG-USP), Brazil, Matão Street, 1226, CEP 05508-090, University City - São Paulo $-S P$ 
${ }^{3}$ Departament of Biological and Agricultural Engineering, Texas A $3 M$ University, 333 Spence St, College Station, Texas, 7r840, USA

${ }^{4}$ Fundação Cearense de Meteorologia e Recursos Hídricos (Funceme), Rui Barbosa Evenue, 1246, CEP 60115221, Aldeota, Fortaleza, CE, Brazil

Corresponding Author : Mariane Chittolina (marianechittolina@gmail.com)

\section{ABSTRACT}

We estimated the seasonal patterns of evapotranspiration (ET) using measured field data in a typical headwater basin and four sub-basins, in subtropical climate region of Serra da Mantiqueira/South-East Brazil, with a multi-instrument hydrometeorological set (standard weather station variables, discharge, soil moisture, and surface-atmosphere turbulent fluxes), towards providing regional data, to our knowledge, hitherto non-existent, of independent ET from micrometeorological methods (eddy covariance EC and Bowen ratio BR), energy balance closure corrections, and water budget based modelling, to discuss the magnitude and seasonality of the most accurate ET possible to be obtained. We had an unsatisfactory closure of the energy balance for the EC method, and the BR method likely also did not meet satisfactory estimates, as both suffered from the non-ideal conditions of the experimental site imposed by secondary atmospheric circulations. The comparison of the mean annual ET among 3 correction methods with the water budget showed an agreement in the range from 2.6 to $2.9 \mathrm{~mm} \mathrm{~d}^{-1}$, that was particularly met by the approaches of Mauder et al. (2013) and Twine et al. (2001), of $2.8 \mathrm{~mm} \mathrm{~d}^{-1}$. These corrections respected upper limits of potential evapotranspiration. Nighttime corrections were not applied, that possibly explains how daily totals of the $\mathrm{H}$ + LE sum overestimated about $9 \%$ of the available energy, that led to an overestimated ET of roughly less than $5 \%$ by those corrections. The seasonal variability of ET ranged from the minimum of $1.3 \mathrm{~mm}$ d- 1 in July, and high fluxes in the wet season of about $3.5 \mathrm{~mm} \mathrm{~d}-1$. The maximum $\mathrm{H}$ flux in September indicated how the onset of rainfall and the quick response of soil moisture recovery prevented $H$ to increase onwards on the rhythm of radiation. Soil moisture appeared to play a key role in not only ET but in controlling the energy partition.

Keywords: tropical hydrology, Atlantic forest, evapotranspiration, soil moisture, water budget

\section{INTRODUCTION}

Long-term (months to years) basin-scale hydrological response is strongly influenced by evapotranspiration (ET), which is the sum of three distinct processes: soil evaporation, rain interception and plant transpiration. The latter manifests itself in the soil-plant-atmosphere system, influencing and being influenced by the interaction of several ecosystem components and processes, such as soil moisture, plant production, runoff generation and rain formation (Wilson and Baldocchi, 2000).

For the water balance at basin-scale in tropical regions, ET represents the system's largest water loss, much to the detriment of the streamflow and aquifer recharge, because more than half of the rain fall returns to the atmosphere as ET (Baker et al., 2021). Consequently, the seasonality and magnitude of ET are important regulators of the water resources available for the ecosystem and for human consumption and use (Ha et al., 2015). Previous reports measured the amount of rain converted to ET is significant in the humid tropical and subtropical regions of Brazil, corresponding to [?]85\% in the Atlantic Forest area of the Mantiqueira mountain range (Pereira, 2014), [?]78\% in the Cerrado area and [?]44\% in the pasture area of the Brazilian Central Plateau (Dias et al., 2015). However, these estimate stem from local studies, which depended on the interval of sampling, climate and characteristics of the basin that influence the water partition to streamflow, acquifer recharge and ET.

Brazil has recently been affected by several regional meteorological droughts, that depleted low flow and supply, for example, in the Central-West Region, Brasilia/2016-2017 (Cunha et al., 2018), in the NorthEast region/2012-2016 (Azevedo et al., 2018), and in the South-East region/2013-2014 (Otto et al., 2016). Therefore, sustainable water management in tropical headwaters requires a better understanding of the evapotranspiration control mechanisms. This is especially important in South-East Brazil, given the climate 
variability and anthropic changes, such as deforestation, urbanisation, afforestation, crop rotation (Chagas \& Chaffe, 2018), the rising water demand increasingly critical for population growth (He et al., 2021), and risks arising from climate change (Magrin et al., 2014; Gesualdo et al. 2019).

Accurate ET estimates are central for sustainable basin management, which can be obtained at two levels: theoretical and field micrometeorological methods on a local scale, and mean water-budget modelling at the basin scale. However, highly accurate and certain estimatives are difficult to obtain given the numerous atmospheric drivers that influence ET and the spatially and temporally variable surface cover conditions. Among some methods, the eddy-covariance (EC) method has been widely used worldwide to assess both ET and the sensible heat flux. However, the lack of energy balance closure is a recurring problem when using the EC method, where the actual landscape conditions, topography, instrumental sampling, and some micrometeorological factors can weaken the hypothetical formulations in ideal circumstances (Foken, 2008). Although some energy balance closure corrections were suggested by Charuchittipan et al. (2014), Mauder et al. (2013) and Twine et al. (2001), those are still under explored due to the lack of other comparative references.

This study discusses the hydrology and emphatically the regime of evapotranspiration in a tropical headwater area in South-East Brazil. A small basin and four sub-basins are covered through a distributed multi-instrument hydrometeorological network focused on climate measures, discharge, soil moisture and micrometeorological methods at the $1 \mathrm{~km}^{2}$ scale (eddy covariance and Bowen ratio), theoretical methods to correct energy balance closure, and water-budget models at the wider basin scale, to estimate as accurately as possible the magnitude and seasonality of actual ET.

\section{MATERIALS AND METHODS}

\section{Area description}

This study investigated of the Ribeirao das Posses basin $\left(12 \mathrm{~km}^{2}\right.$, altitude between 938 and $1456 \mathrm{~m}$ a.s.l.), herein referred to as PO, and four of its sub-basins: Q1, Q2, Q3, and Q4 that had 41-343 ha basin areas, average slopes of $17-48 \%$, and a forest area between $24 \%$ and $47 \%$ located in the Serra da Mantiqueira, in the Atlantic Forest Biome, Brazil (Fig. 1). The soil cover of the basin comprises mainly pasture ([?]60\%) with eucalyptus fragments and forest restoration areas with native flora ([?]40\%) (Fig. 2a). The basin has been pioneering in paid environmental services projects in Brazil since 2009 (Richards et al., 2015). The climate is tropical at altitude (Cwb-Koppen) (Alvares et al., 2014), with hot and rainy summers. Red Ultisol and its variations (Red Yellow Ultisol and Yellow Argisol) are the predominant soil class, occupying approximately $78 \%$ of the area (Silva et. al., 2019) (Fig. 2b).

\section{Field measurements}

From 2017 to 2021, meteorological variables were measured in a network of automatic weather stations (WXT520 Weather Transmitter, Vaisalla, Vantaa, Finland) distributed in the basin (Fig. 1b, c and Fig. 3d) (Martin et al. 2018), with sampling every 2 min and averaged hourly, i.e. air temperature (acc. +-0.4degC), horizontal wind speed (acc. +-3\%) and direction (acc. +-3\%), relative humidity (acc. +-5\%), atmospheric pressure (acc. $+-1 \mathrm{hPa}$ ) and precipitation (acc. $+-5 \%$ ). The daily spatial precipitation in the PO basin was re-estimated in a regular grid with a resolution of $100 \mathrm{~m}^{2}$ by interpolating the automatic stations using the inverse distance weighting method (IDW) (Pebesma, 2004; Graler, Pebesma and Heuvelink, 2016). The global incoming solar irradiance (CM22 Kipp \& Zonen) and net radiation balance (Net Lite) were measured at the top of the flux tower. The estimates of the turbulent atmospheric fluxes of sensible heat flux $(\mathrm{H})$ and latent heat flux (LE) were made with 30 min averages while using the Eddy covariance (EC) and Bowen-ratio (BR) micrometeorological methods. Measurements were performed using a vertical flux tower profile of air temperature and humidity (Vaisalla WXT, Finland), with a $\mathrm{CO}_{2}$ and $\mathrm{H}_{2} 0$ open-path gas analyser with a 3D sonic anemometer (IRGA; model LI-7500, Licor, Inc., Lincoln, USA) at 9-m height in the top of a flux tower located at the Q2 basin mouth (Fig.1.b, c, and Fig. 3e, f). The soil heat flux was measured with the averages of three sensors near the tower (Hukseflux, Netherlands). Hydrological discharge in all basins was estimated based on water-level measurements at the mouth of each basin (Fig. 1b and Fig. 3b-c) using 
an automatic level sensor (Solinst Level Logger 3001). We estimated an spatially averaged moisture index, termed shallow soil moisture, by integrating measurements at depths of 10,20 , and $30 \mathrm{~cm}$ for all probes and, similarly for the intermediate soil moisture, using measurements at 40,60, and $100 \mathrm{~cm}$, and used the daily average of the soil wetness index (SWI), equal to ( $\vartheta \mathrm{i}$ - $\vartheta$ minimum absolute) / ( $\vartheta$ maximum absolute $\vartheta$ minimum absolute), which ranges from 0 to $1, \vartheta \mathrm{i}$ is the spatially averaged volumetric soil moisture at day I. We evaluated three flux-correction methods, which distribute the residual energy available in the system between the sum of the LE and $\mathrm{H}$ fluxes, in order to mitigate the effect of the lack of energy balance closure of the EC method, inspired by Charuchittipan et al. (2014), Mauder et al. (2013) and Twine et al. (2001), herein referred to as CHA, MAU and TWI, respectively. For comparative purposes, we also took hourly field measurements using the BR method, made hourly theoretical estimates using the Penman-Monteith FAO56 method (here called PM), and eventually estimated monthly ET using the water-budget method (herein referred to as WBM), as described next.

\section{Eddy-covariance method}

The EC method is a micrometeorological technique that measures energy (heat and water), $\mathrm{CO}_{2}$ and momentum exchanges between the atmosphere and surface. Latent heat (LE) and sensible heat $(\mathrm{H})$ fluxes were estimated using the covariance between vertical fluctuations in wind speed and water-vapour concentration for LE and wind with air-temperature fluctuations for $\mathrm{H}$. The fluxes were estimated in a 30 min scale, and were then averaged hourly. We used software EddyPro (LI-COR Inc.) to calculate H and LE at 30 min intervals from the $20 \mathrm{~Hz}$ measure of raw data with $\mathrm{u}, \mathrm{v}, \mathrm{w}, \mathrm{T}, \mathrm{q}$, that was processed applying coordinate rotations, despiking, time lag compensation using cross-correlation maximization, WPL corrections, and high and lowpass filtering using block averaging. The sum of the LE and $\mathrm{H}$ fluxes of EC is usually underestimated, i.e., less than the available energy, understood here as the sum of net radiation (Rn), ground heat flux $(\mathrm{G})$ and air heat storage $(\mathrm{J})$. We applied the CHA, MAU and TWI methods for events with available energy $>20 \mathrm{~W}$ $\mathrm{m}^{-2}$ and considered corrected or uncorrected values within the maximum and minimum thresholds (Table 1-Sup Mat).

Correções por Twine et al. (2000)

This method assumes that the available energy measurements $(\mathrm{Rn}-\mathrm{G}-\mathrm{J})$ are the representative of the EC footprint area, so the $\mathrm{H}$ and $\mathrm{LE}$ fluxes can be corrected by the Bowen Ratio (BR), with the corrected $\mathrm{H}_{\text {cor }}$ and $\mathrm{LE}_{\mathrm{cor}}$ in the following way: $\beta=\frac{H_{\mathrm{obs}}}{L E_{\mathrm{obs}}}(1) L E_{\mathrm{cor}}=\frac{\mathrm{Rn}-G-J}{1+\beta}(2) H_{\mathrm{cor}}=\mathrm{Rn}-G-J-L E_{\mathrm{cor}}(3)$

\section{Corrections by Mauder et al. (2013)}

As in Twine et al. (2000), Mauder et al. (2013) describes that the Bowen ratio is maintained before and after corrections, and the systematic error is equally distributed for $\mathrm{H}$ and $\mathrm{LE}$ according to the $\mathrm{C}$ coefficient, with the corrected $H_{\mathrm{cor}}$ and $L E_{\mathrm{cor}}$ in the following way: $H_{\mathrm{cor}}=\frac{H_{\mathrm{obs}}}{C}(4) L E_{\mathrm{cor}}=\frac{L E_{\mathrm{obs}}}{C}(5) C=\frac{\sum_{i-1}^{k}\left(H_{i}+L E_{i}\right)}{\sum_{i-1}^{k}\left(R n_{i}-G_{i}-J_{i}\right)}(6)$ where the coefficient $\mathrm{C}$ was calculated based on 30min fluxes on a daily basis, i.e., on 48 values that vary daily all year round.

Corrections by Charuchittipan et al., (2014)

According to Charuchittipan et al. (2014), the residue allocation depends on the ratio between the sensible heat flux $\mathrm{H}$ and buoyancy flux, thus attributing a greater residual energy (Res) fraction to the $\mathrm{H}$ flux, such that: $H_{\mathrm{cor}}=H_{\mathrm{obs}}+f_{\mathrm{EB}} \operatorname{Res} \quad(7) L E_{\mathrm{cor}}=L E_{\mathrm{obs}}+\left(1-f_{\mathrm{EB}}\right) \operatorname{Res} \quad(8) f_{\mathrm{EB}}=\frac{H_{\mathrm{obs}}}{B}=\left(1+0.61 \bar{T} \frac{{ }^{\circ} \pi}{\lambda \mathrm{Bo}}\right)(9)$ where, Res $=\mathrm{Rn}-(\mathrm{H}+\mathrm{LE}+\mathrm{G}+\mathrm{J})]$ evaluated in a hourly basis; $\mathrm{B}=$ buoyancy $\left(\mathrm{m} \mathrm{K} \mathrm{s}^{-1}\right)$; Bo = Bowen ratio; $\mathrm{cp}=$ specific heat at constant air pressure $\left(\mathrm{J} \mathrm{kg}^{-1} \mathrm{~K}^{-1}\right)=1005+1.82 \mathrm{q} ; \mathrm{q}=$ absolute specific humidity; $\lambda=$ latent heat of vaporisation $\left(\mathrm{J} \mathrm{kg}^{-1}\right)$.

\section{Bowen ratio-energy balance method}

The Bowen ratio-energy balance technique (Bowen, 1926) was used as a reference to validate the remaining methods. For its estimation, we used the vertical profile of temperature and water-vapour pressure installed 
in the flux tower, measured every $10 \mathrm{~min}$ and resampled each $30 \mathrm{~min}$. The $\mathrm{BR}$ was measured according to: $\beta=\frac{H}{\mathrm{LE}}=\gamma \frac{T}{e} \quad(10)$

$[?] \mathrm{T}$ and [?] e denote the differences in air temperature $\left({ }^{\circ} \mathrm{C}\right)$ and water-vapour pressure $(\mathrm{kPa})$ between measurement levels $\mathrm{z} 1$ and $\mathrm{z} 2 ; \mathrm{t}_{1}$ and $\mathrm{t}_{2}=$ air temperature $\left({ }^{\circ} \mathrm{C}\right)$ at levels 1 and 2 , respectively; ea $\mathrm{a}_{1}$ and $\mathrm{ea}_{2}=$ water-vapour pressure $(\mathrm{kPa})$ at levels 1 and 2 , respectively; $\gamma=$ psychrometric constant (Allen et al., 1998). So, the LE and $\mathrm{H}$ fluxes were estimated as:

$$
\begin{aligned}
\mathrm{LE} & =\frac{\mathrm{Rn}-G-J}{1+\beta} \\
H & =\frac{\mathrm{Rn}-G-J}{1+1 / \beta}
\end{aligned}
$$

The flux consistency analysis in this method excluded $\beta$ estimates between -0.5 and -1.5 , based on Perez et al. (1999).

\section{Sensible Heat Storage}

The sensible heat storage $\left(\mathrm{J}\right.$ in $\left.\mathrm{W} \mathrm{m}{ }^{-2}\right)$ was estimated like: $J=\rho \cdot \mathrm{cp} \cdot \frac{T}{t} z$ (13) where, $\rho=$ mass density $\left(\mathrm{kg} \cdot \mathrm{m}^{-3}\right)=1.2 ; \mathrm{cp}=$ specific heat at constant air pressure $\left(\mathrm{J} \mathrm{kg}^{-1} \mathrm{~K}^{-1}\right)=1004$; [?]T is the average time difference in air temperature ( $\operatorname{deg} C)$ of levels z1 and $\mathrm{z} 2$, from the beginning of time t1 to the end of the flow estimation time $\mathrm{t} 2$; [?] $\mathrm{T}$ is the difference between $\mathrm{z} 1$ and $\mathrm{z} 2$, in meters.

\section{Penman-Monteith method}

The reference ET, considered as potential evapotranspiration, was estimated by Penman-Monteith method (FAO-56) (Allen et al., 1998), according to:

$E T_{o}=\frac{0.408(\mathrm{Rn}-G)+\gamma \frac{900}{T+273} u_{2}\left(e_{s}-e_{a}\right)}{+\gamma\left(1+0.34 u_{2}\right)}$

where, $\mathrm{ET}_{\mathrm{o}}$ is expressed in $\mathrm{mm} \mathrm{d}^{-1} ; \mathrm{T}=$ average daily temperature $(\operatorname{degC}) ; \mathrm{U} 2=$ wind speed $\left(\mathrm{m} \mathrm{s}^{-1}\right)$ at $2-\mathrm{m}$ height; $\mathrm{e}_{\mathrm{s}}=$ saturation vapour pressure $(\mathrm{kPa}) ; \mathrm{e}_{\mathrm{a}}=$ actual vapour pressure $(\mathrm{kPa}) ;[?]=$ slope of the vapour pressure curve versus temperature $\left(\mathrm{kPa}^{-1}\right) ; \gamma=$ psychrometric constant $\left(\mathrm{kPa}^{-1}\right)$.

\section{Water Budget Method}

We used the water budget method (herein referred to as WBM) to assess monthly and annual ET variations in more detail based on field measurements and on a parsimonious hydrological balance model (Vandewiele, $\mathrm{Xu}$ et al. 1992). The model forcing factors were provided by the monthly values of potential evapotranspiration $\left(\mathrm{E}_{\mathrm{tp}}\right)$, precipitation $\left(\mathrm{P}_{\mathrm{t}}\right)$ and streamflow $\left(\mathrm{Q}_{\mathrm{tm}}\right)$, and were estimated the streamflow $\left(Q_{t c}\right)$, actual evapotranspiration $\left(R_{t}\right)$, direct runoff $(\mathrm{Qf})$, slow runoff (Qs) and water storage $(M)$. Storage $\left(\mathrm{M}_{\mathrm{t}}\right.$ at the end of month $\left.\mathrm{t}\right)$ is expressed in $\mathrm{mm}$ month $^{-1}$ and summarises the basin's hydrological memory according to the water balance: $M_{t}=M_{t-1}+P_{t}-R_{t}-Q_{t}$ (15) Actual evapotranspiration is extrapolated from the monthly potential evapotranspiration $\left(\mathrm{E}_{\mathrm{t}}\right)$ and water available for evapotranspiration during month $\mathrm{t}\left(\mathrm{W}_{\mathrm{t}}\right)$. The latter is equated as follows: $W_{t}=P_{t}+M_{t-1}$ (16) where $\mathrm{M}_{\mathrm{t}-1}$ denotes soil storage at the beginning of month t. The model defines two possible equations to estimate real evapotranspiration: $R_{t}=\left\lceil\mathrm{E}_{t}\left(1-a_{1}^{\frac{W_{t}}{E_{t}}}\right), W_{t}\right\rceil(17) R_{t}=\left\lceil\mathrm{W}_{t}\left(1-a_{1}^{E_{t}}\right), E_{t}\right\rceil(18)$ where $\mathrm{a}_{1}$ is a positive parameter, limited to 0 [?] a1 [?] 1 , which is the characteristic of the studied basin. The equations are such that the actual evapotranspiration increases with $\mathrm{E}_{\mathrm{t}}$ and $\mathrm{W}_{\mathrm{t}}$. The flux $\mathrm{Qt}$ is divided into stormflow (Qf) and baseflow (Qs). These terms are approximated to baseflow and streamflow, which are calculated using the following equations: $Q_{s}=a_{2}\left(S_{t-1}\right)^{b_{1}} \quad(19) Q_{f}=a_{3}\left(S_{t-1}\right)^{b_{2}}\left\lceil P_{t}-E_{t}\left(1-\exp \left(\frac{-P_{t}}{E_{t}}\right)\right)\right\rceil(20)$ where $a_{2}, a_{3}, b_{1}$ and $b_{2}$ are positive parameters. Baseflow depends on basin storage during the previous month. The stormflow equation considers that a greater storage in the previous month $\left(\mathrm{M}_{\mathrm{t}-1}\right)$ causes a higher percentage of rain to become runoff.

RESULTS AND DISCUSSION 
3.1. Meteorological variabilityThe region has a climatological dry season between May and August (shaded in Fig. 4) and average rainfall of $1600 \mathrm{~mm} \mathrm{y}^{-1}$. The average rainfall from 2017 to 2021 was 1505 $\mathrm{mm} \mathrm{y}^{-1}$ (Fig. 4b), and the annual average temperature was $18.4^{\circ} \mathrm{C}$, with the maximum and minimum daily temperatures varying predominantly between [?]14degC and $30 \mathrm{deg} \mathrm{C}$ and from [?]10degC to $20 \mathrm{deg} \mathrm{C}$, respectively (Fig. 4a). The relative humidity daily average varied seasonally from about $55 \%$ (dry season) to $85 \%$ (rainy season) (Fig. 4c). The wind speed at 2-m height was the highest between September and October (Fig. 4d) according to two typical circulation modes: the weaker northeasterlies generally from morning to mid-afternoon and the stronger southeasterlies from mid-afternoon to evening (Martin et al., 2018). Incident solar irradiance was strongly affected by solstices and intra-seasonal cloud cover variability, with daily maximums ranging from 220 to $350 \mathrm{~W} \mathrm{~m}^{-2}$ in the wet/dry seasons, respectively (Fig. 4e), and was also strongly correlated with the temporal variation of the net radiation (Fig. 1-Mat Sup).

\subsection{Surface energy budget closure}

We evaluated the energy balance closure comparing the sum of the sensible heat flux $(\mathrm{H})$ and latent heat flux (LE) with the available energy obtained by integrating the radiation balance, soil heat flux and air column heat storage variation $(\mathrm{Rn}-\mathrm{G}-\mathrm{J})$. With linear fittings of hourly measurements, we obtained the EC method closure at 56\% (Fig. 5a), a typically low result, which we considered unsatisfactory. We assumed this low closure was probably due to the steep topography and the existence of secondary valley-mountain circulations (Martin et al., 2018). This was somehow expected and motivated us to try to improve the turbulent fluxes $\mathrm{H}$ and LE by comparison with the correction methods CHA, MAU and TWI, and others (BR, PM and WBM) (see 2.3-2.6). As expected, the closure of the hourly TWI and CHA methods came close to $100 \%$ under the conditions of positive available energy, the characteristic of daytime periods (Figs. $5 \mathrm{~b}, \mathrm{~d})$. With negative available energy, usually at night, we did not apply the TWI and CHA corrections, which maintained the dispersion of EC measurements, but which nevertheless involved comparatively small amounts of energy compared to corrections at daytime. The closure by hourly basis with MAU method was $90 \%$ and, therefore, quite satisfactory, even if characterized by pronounced scattering around the fitted regression, due to the intraday hourly variability, which occurs in relation to the daily averaged correction criterion we used (Fig. 5c). The daily totals using the hourly correction of the 3 methods showed closures very close to each other, varying from [?]108\% to $110 \%$ (Figs. $5 \mathrm{f}-\mathrm{h}$ ), hence a notable improvement in relation to the $56 \%$ EC closure (Fig. 5e). We noted how the daily totals slightly overestimated the closure, probably associated with the lack of hourly nighttime correction. The LE and $\mathrm{H}$ estimates using the EC method and the corrections (CHA, MAU and TWI) were conveniently compared with the BR method (Fig. 2-Mat. SUP), an independent and direct field estimate, which principally closes the energy balance, thus opportune to help addressing our question. The EC and CHA methods were the ones that most underestimated BR, by $-33 \%$ and $-23 \%$, respectively. Likewise, the $\mathrm{H}$ flux of the EC method also greatly underestimated the BR ([?]-49\%), whereas the CHA method overestimated BR with a difference of $+30 \%$. The lack of closure we identified showed that, at least compared to $\mathrm{BR}$, the reduction was not predominant in only one flux type (H or LE) but more probably distributed between them. The TWI and MAU corrections showed a very similar comparison with each other, when overestimating LE of BR by $+12 \%$ and $+8 \%$, while underestimating $\mathrm{H}$ of BR by $-15 \%$ and $-18 \%$, respectively. In summary, the comparisons with the BR method showed that the CHA tended to greatly increase the $\mathrm{H}$ flux and underestimate the ET, whereas the TWI and MAU corrections markedly tended to raise ET to the detriment of $\mathrm{H}$, although the latter had a considerable increment.

\subsection{Energy partition and seasonality of fluxes $H$ and LE}

We gap-filled the hourly time series of field fluxes (EC and BR), closing corrections (TWI, MAU and CHA) and PM, with the purpose of better evaluating the seasonality, estimating the annual average, avoiding bias due to the greater or lesser amount of data in specific months of the year, accordingly to the method, and eventually comparing micrometeorological estimates more evenly with the annual/monthly integrated estimates of WBM. We tested a simple linear model of the hourly fluxes ( $\mathrm{H}$ or LE) dependent on the available energy. With the model we also aimed to address the estimations of the available energy effectively distributed between LE or H. The method, despite simplified, showed a reasonable performance, probably 
the effect of a pronounced seasonality of the radiative energy, small variation in the leaf area index year around (not shown), and high dependence between net radiation to $\mathrm{RH}$ and wind speed on a seasonal basis (Fig. 4). For all tested methods, the linearity of $\mathrm{LE}$ or $\mathrm{H}$ with $\mathrm{Rn}-\mathrm{G}-\mathrm{J}$ was statistically significant (p-value $<0.01$, Fig. 3-Mat Sup). In a simple assessment based on the slope coefficient, the percentage of available energy attributed to LE was low in the EC (33\%) and CHA (38\%), and, for other methods, were very close to each other, with TWI, MAU and BR ranging from $54 \%$ to $57 \%$. The partition of energy to the $\mathrm{H}$ flux was the lowest in the EC (23\%), followed by TWI, MAU and BR $(36 \%, 38 \%$ and $43 \%)$ and the highest in CHA $(57 \%)$.

From the gap-filled time series with the statistical model, we obtained a well-defined and discriminated seasonal variation pattern between the methods. The seasonality of LE, as of the TWI and MAU methods, was visibly tied to the radiative energy, with minimums in winter and maximums in summer (Fig. 6a). The LE was minimum in July, and, during [?]5 months from August to December, slowly reached up the highest flux in January of about $4 \mathrm{~mm} \mathrm{~d}-1$. For the $\mathrm{H}$ flux, the seasonality was very asymmetrical and showed marked differences to LE. For the TWI and MAU methods, the H term is nearly steady during approximately 5 months in the wet season (December to April). Thereafter, $\mathrm{H}$ drops slowly until it reaches its low in mid-July, then quickly reaching its highs in less than 2 months until September.

Interestingly, for the TWI and MAU estimates, from January through April the ET was similar to those of PM, and from June to August similar to those of BR. Especially with respect to the comparison to PM, it likely appears to exist a second control, beyond the available energy, that our statistical model overlooked. We suggest this control can be closely related to the soil moisture, whose variation we discuss in 3.4, and the role it plays in the evapotranspiration. In all methods, we particularly noticed a maximum $\mathrm{H}$ flux by early September, concurrent with the annual minimum soil moisture, which suggests how this may considerably influence not only the seasonality of $\mathrm{H}$, but in general the energy partition.

For the LE flux, the EC method showed the lowest estimate of all, followed respectively by CHA and BR. Likewise, the estimates of TWI and MAU were high and very close to each other (Fig. 6a), which wholly corroborates our previous methods comparison. The PM method was the highest, consistently with the premise to express the potential evapotranspiration. For the $\mathrm{H}$ flux, the EC method produced the lowest estimate, largely due to its low closure, followed by TWI and MAU, that were very close to each other, and then BR, respectively, and finally CHA with the highest estimate (Fig. 6b).

The annual ET amplitude was well marked in all methods but with differences between them (Fig. 6a). The smallest amplitude was [?]1.5 $\mathrm{mm} \mathrm{d}^{-1}$ of EC (from 0.9 to $2.4 \mathrm{~mm} \mathrm{~d}^{-1}$ variation) and the largest was [?] $2.4 \mathrm{~mm}$ $\mathrm{d}^{-1}$ of TWI and MAU (from 1.4 to $3.8 \mathrm{~mm} \mathrm{~d}^{-1}$ variation), which reflects the weight of closure correction on LE by these methods. Likewise, the annual amplitude of $\mathrm{H}$ (Fig. 6b) was the lowest [?]15 $\mathrm{W} \mathrm{m}^{-2}$ using EC (from 15 to $30 \mathrm{~W} \mathrm{~m}^{-2}$ variation) and the highest [?] $40 \mathrm{~W} \mathrm{~m}^{-2}$ using CHA (from 35 to $75 \mathrm{~W} \mathrm{~m}^{-2}$ variation), which also results from how the latter method attributed more energy to $\mathrm{H}$.

\subsection{Water balance}

To better understand the water balance and its link with the surficial energy balance, we show the variation of monthly precipitation $(\mathrm{P})$, specific discharge $(\mathrm{Q})$ and soil moisture $(\mathrm{SM})$ in Fig. 7. It is shown that $\mathrm{P}$ peaked in the rainy season between [?]250 and $400 \mathrm{~mm} \mathrm{mo}^{-1}$, and that Q peaked between January and March depending on the year. In the summer of all years from 2015 to 2018, Q and P peaked mostly concurrently, with Q delayed for approximately 2 months for the remaining years, from 2019 to 2021. In a companion paper, Chittolina et al. (2022) showed that Q peaked identically for all the studied basins and, furthermore, how there were remarkable thresholds of either SM and water-table depth conditioning the stormflow generation in all the basins, which impacted the monthly streamflow phase. In 2018 and 2019, for example, there was a visible lag between SM and Q, with the minimum SM in August (Fig. 7), followed by a rapid recovery with the onset of rains in September, approximately 3 months before the recovery of Q. In turn, a likely result of modest stormflow is how rainfall is about to be driven mostly to infiltration and soil moisture storage, especially in the dry-to-wet season transition, which consequently helps to increase LE 
and reduce H. Such rapid response of SM to rain and a firm stationarity during the rainy season may partly explain the seasonal pattern of the LE and H energy fluxes, as shown in Fig. 6.

To evaluate the mean annual ET of each basin, we used the estimates from the monthly ET time series calculated with the WBM, except for Q1 basin where the length of field data was not sufficient to provide model calibration, and compared to ET estimated simply as the residual of the annual balance (= P - Q), shown in Fig. 8a. According to the WBM, the highest mean ET was $3.3 \mathrm{~mm} \mathrm{~d}^{-1}$ for the PO basin and the lowest 2.6, 2.9 and $2.9 \mathrm{~mm} \mathrm{~d}^{-1}$ for the Q2, Q3 and Q4 basins, thus showing how the sub-basins were close to each other and different from the larger PO. The mean residual ET was generally below the modelled ET, except for the Q2 basin where it was slightly higher. These differences resulted from the calculation of the storage variation, which on a mean annual basis was negative, between -5.0 and $-8 \mathrm{~mm} \mathrm{mo}^{-1}$ (except being slightly positive for Q2 of $+0.2 \mathrm{~mm} \mathrm{mo}^{-1}$ ) (Fig. $8 \mathrm{~b}$ ). This means how water storage depletion resulted from several years with below average rainfall (2015 to 2021-Fig. 7), which exhausted the water system (SM and groundwater). Incidentally, Domingues et al. (2022) showed how the Jaguari River basin, of which Ribeirao das Posses is a tributary, experienced historical serial meteorological droughts, between 2013 and 2021 , leading to reduction of the low flow, and directly associated to the pronounced decrease of terrestrial water storage and aquifer recharge between 2018 and 2021.

We compared the mean annual ET among all micrometeorological methods and with the WBM according to the hydrological model per basin (Fig. 9, Table 1). ET varied remarkably little within the Q1, Q2, Q3 and Q4 basin group (from 2.6 to $2.9 \mathrm{~mm} \mathrm{~d}^{-1}$ ), which aligned well with the $2.8 \mathrm{~mm} \mathrm{~d}^{-1} \mathrm{TWI}$ and MAU values. In this range, the estimates of EC $\left(1.8 \mathrm{~mm} \mathrm{~d}^{-1}\right)$ and CHA $\left(2.1 \mathrm{~mm} \mathrm{~d}^{-1}\right)$ fell considerably below that set, implying a very likely underestimation of the actual ET if extrapolated at the basin scale. Additionally, the ET of $3.1 \mathrm{~mm} \mathrm{~d}^{-1}$ with the PM method surpassed all others, and because it is an upper threshold reference associated to potential evapotranspiration, it is suggested that the TWI, MAU and WBM estimates for those basins did not exceed the theoretical maximum limits.

To the PO basin, the mean ET was the highest of $3.3 \mathrm{~mm} \mathrm{~d}^{-1}$ (Fig. 9, Table. 1), notably above the remaining methods, as TWI and MAU, and especially PM, thus indicating a likely overestimation. We noticed that the high ET in the PO resulted from the measured Q $\left(0.9 \mathrm{~mm} \mathrm{~d}^{-1}\right)$ being the lowest among all (1.4 to 1.7 $\left.\mathrm{mm} \mathrm{d}^{-1}\right)$. Also, the mean annual runoff coefficient of PO was $22 \%$, that fell below all others (33\% to $\left.38 \%\right)$ (Table 1).

We compared the evaporative index EI of the basins (Table 1), that varied from the highest in PO of $80 \%$, to the range of other basins, that was relatively narrow from $59 \%$ to $67 \%$. We compared the long term inventory based data of rainfall and discharge in the Mantiqueira Hydrological Unity (CERH, 1999), a set of regional watersheds totaling $972 \mathrm{~km}^{2}$, with $\mathrm{P}=1950 \mathrm{~mm} \mathrm{yr}^{-1}$ and $\mathrm{Q}=1020 \mathrm{~mm} \mathrm{yr}^{-1}$, thus with the residual ET showing $\mathrm{EI}=48 \%$. The later was less than the range of our sub-basins, and derived from a mean precipitation well above the ones in our sampling (from 1496 to $1612 \mathrm{~mm} \mathrm{yr}^{-1}$, Table 1), which tended to reduce the fraction of $\mathrm{ET}$ in the simple water budget.

\section{CONCLUSIONS}

Our study attempted to understand the patterns of evapotranspiration (ET) and its role on the hydrological response of a small basin ([?] $12 \mathrm{~km}^{2}$ ) and four of its sub-basins ([?] 0.4 to $3.4 \mathrm{~km}^{2}$ ), in a region with a subtropical climate, Serra da Mantiqueira montane region in the Atlantic Forest biome of South-East Brazil. For this purpose, we measured a comprehensive set of hydrometeorological variables, namely standard weather station variables, discharge, soil moisture, and surface-atmosphere turbulent fluxes with eddy covariance and Bowen ratio. We provided typical regional data and interpretation, to our knowledge, hitherto non-existent, of estimates with independent methods, from micrometeorological, energy balance closure corrections and water budget based modelling, to discuss the magnitude and seasonality of the most accurate ET as possible to be obtained.

We had an unsatisfactory closure of the energy balance for the EC method, and achieved substantial improvement while testing other methods. The BR method possibly did not provide the most accurate estimate 
of $\mathrm{H}$ and LE we pursued, as it also suffered from the non-ideal conditions of the experimental site, imposed by secondary circulations that drive horizontal transports of heat and moisture not accounted in our instrumental design. The comparison of the mean annual ET among all micrometeorological methods/corrections and with the water budget showed an agreement in the range from 2.6 to $2.9 \mathrm{~mm} \mathrm{~d}^{-1}$, that was particularly met by the approaches of TWI and MAU of $2.8 \mathrm{~mm} \mathrm{~d}^{-1}$. These correction methods respected upper limits based on theoretical premises of potential evapotranspiration. Nighttime corrections were not applied, that possibly explains how their daily totals of the $\mathrm{H}+\mathrm{LE}$ sum overestimated about $9 \%$ of the available energy. Based on the percentage of available energy attributed to LE, it is proposed that TWI and MAU overestimated ET by roughly less than $5 \%$.

Especially for the PO basin, the ET with WBM was above the range outlined by the selected methods. We hypothesize firstly of an instrumental systematic error when measuring the flow at the PO outlet, biased for underestimation. We carefully tried to avoid this issue by comparing our measurements with those of the National Water Agency manually taken with a conventional linimetric ruler during field campaigns, which matched considerably with each other. Our measurements were automatically taken by a traditional Parshall flume system, highly accurate for low and medium fluxes, and which, in turn, generally account for most of the average basin flow in these tropical regions. A second hypothesis could be tied to different basin surface covers (where higher forest concentrations could explain higher ET rates) or soil type differences, both insufficient to explain the variation, as reported in the companion paper of Chittolina et al. (2022). These two hypotheses seemed unlikely and lead us to assume a third hypothesis: groundwater flux exited the PO basin to recharge larger scale deep aquifers without passing through the surface outlet. Such phenomena are common in basins measurement, depending on its geology and scale (Schaller \& Fan, 2009), and can only be noticed under extensive hydrological monitoring that allows several processes to be evaluated simultaneously.

Our selected estimates as of TWI and MAU presented a seasonal variability of ET ranging from the annual minimum of $1.3 \mathrm{~mm} \mathrm{~d}^{-1}$ in July, and high fluxes during [?]5 months in the wet season (December to April) of about $3.5 \mathrm{~mm} \mathrm{~d}^{-1}$. The maximum $\mathrm{H}$ flux in September indicates how the onset of rainfall and the quick response of soil moisture recovery prevented $\mathrm{H}$ to increase onwards on the rhythm of radiation. Soil moisture appeared to play a key role in the energy partition during the dry-to-wet season transition. It is well known how soil moisture stress acts as a limiting factor for transpiration, in parallel with the drastic reduction of both the soil evaporation and the rain interception losses that typically occur during the dry season.

\section{ACKNOWLEDGEMENTS}

This research was supported by Sao Paulo Research Foundation (FAPESP, grants 2015/50682-6, 2016/163580, 2019/17179-0, and 2020/04060-1).

\section{CONFLICTS OF INTEREST}

The authors declare that they have no known conflicts of interest or personal relationships that could have appeared to influence the work reported in this paper.

\section{REFERENCES}

Allen R. G., Pereira L. S., Raes D, Smith M. (1998) Crop evapotranspiration-Guidelines for computing crop water requirements-FAO Irrigation and drainage paper 56. Food and Agriculture Organization of the United Nations .

Alvares, C. A., Stape, J. L., Sentelhas, P. C., de Moraes Goncalves, J. L., \& Sparovek, G. (2014). Koppen's climate classification map for Brazil. Meteorologische Zeitschrift, 22 , 711-728.

Azevedo, S. C., Cardim, G. P., Puga, F., Singh, R. P., \& da Silva, E.A. (2018). Analysis of the 2012-2016 drought in the northeast Brazil and its impacts on the Sobradinho water reservoir. Remote Sensing Letters , 9, 438-446. https://doi.org/10.1080/2150704X.2018.1437290

Baker, J. C., Garcia-Carreras, L., Gloor, M., Marsham, J. H., Buermann, W., da Rocha, H. R., Nobre, A. D., Araujo, A. C. \& Spracklen D. V. (2021). Evapotranspiration in the Amazon: spatial patterns, seasonality, 
and recent trends in observations, reanalysis, and climate models.Hydrology and Earth System Sciences , 25, 2279-2300. https://doi.org/10.5194/hess-25-2279-2021

Bowen, I. S (1926). The ratio of heat losses by conduction and by evaporation from any water surface. Phyical Review. 27, 779-787. https://doi.org/10.1103/PhysRev.27.779

CERH (CONSELHO ESTADUAL DE RECURSOS HIDRICOS) Relatorio de situacao dos recursos hidricos do Estado de Sao Paulo. Comite do Plano Estadual de Recursos Hidricos. Estado de Sao Paulo, 1999.

Chagas, V. B. P., \& Chaffe, P. L. B. (2018). The role of land cover in the propagation of rainfall into streamflow trends. Water Resources Research , 54, 5986-6004. https://doi.org/10.1029/2018WR022947

Charuchittipan, D., Wolfgang, B., Mauder, M., Leps, J. P. \& Foken, T. (2014). Extension of the Averaging Time in Eddy-Covariance Measurements and Its Effect on the Energy Balance Closure. Boundary-Layer Meteorology volume, 152(3), 303-27. https://doi.org/10.1007/s10546-014-9922-6

Chittolina, M., Domingues, L. M., Lobo, G. A. \& Rocha, H. R. (2022). Hydrological response of a headwater catchment in southeastern Brazil Part I: Patterns of rainfall-runoff and stormflow relationships. Hydrologial Processes special issue: Processes and Patterns in Tropical Hydrology . [Manuscript submitted for publication].

Cunha, A. P. M. A., de Barros Brito, S. S., Neto, G. G. R., \& dos Santos Alvala, R. C. (2018). As secas entre 1963 E 2017 no Distrito Federal, Brasil. Anuario do Instituto de Geociencias, UFRJ, 41(2), 487-498. https://doi.org/10.11137/2018_2_487_498

Da Rocha, H. R., Goulden, M. L., Miller, S. D., Menton, M. C., Pinto, L. D. V. O., de Freitas, H. \& Figueira, A. M. E. Silva. (2004). Seasonality of water and heat fluxes over a tropical forest in eastern Amazonia. Ecological Applications , 14(43), Supplement, S22-S32. https://doi.org/10.1890/02-6001

Dias, L. C. P., Macedo, M. N. Costa, M. H., Coe, M. T. \& Neill, C. (2015). Effects of land cover change on evapotranspiration and streamflow of small catchments in the Upper Xingu River Basin, Central Brazil. Journal of Hydrology: Regional Studies , 4(B), 108-122. https://doi.org/10.1016/j.ejrh.2015.05.010

Domingues, L. M. \& Rocha, H. (2022) Serial droughts and loss of basin hydrological resilience: the case of water inflow into Cantareira reservoirs during 2013 to 2021 in Brazil [Manuscript submitted for publication].

Foken, T. (2008). The energy balance closure problem: an overview.Ecological Applications , 18(6), 13511367. https://doi.org/ 10.1890/06-0922.1

Foken, T., Mauder, M., Liebethal, C., Wimmer, F., Beyrich, F., Leps, J. P., Raasch, H.A.R., De Bruin, W.M.L. Meijninger, J. \& Bange, J. (2010). Energy balance closure for the LITFASS-2003 experiment.Theoretical and Applied Climatology , 101(1), 149-160.

Graler B., Pebesma E., \& Heuvelink G. (2016). Spatio-Temporal Interpolation using gstat. The R Journal, 8(1), 204-218.

Ha, W., Kolb, T. E., Springer, A. E., Dore, S., O’Donnell, F. C., Morales, R. M., Lopez, S. M. \& Koch, G. W. (2014). Evapotranspiration comparisons between eddy covariance measurements and meteorological and remote-sensing-based models in disturbed ponderosa pine forests.Ecohydrology, Published online in Wiley Online Library. https://doi.org/10.1002/eco.1586

He, C., Liu, Z., Wu, J. Pan, X., Fang, Z., \& Bryan, B.A. (2021). Future global urban water scarcity and potential solutions. Nature Communications , 12. https://doi.org/10.1038/s41467-021-25026-3

Magrin, G. O., Marengo, J. A., Boulanger, J. -P., Buckeridge, M. S., Castellanos, E., Poveda, G., Scarano, F. R., \& Vicuna, S.(2014). Central and South America. In V. R. Barros, C. B. Field, D. J. Dokken, M. D. Mastrandrea, K. J. Mach, T. E. Bilir, M. Chatterjee, K. L. Elbi, Y. O. Estrada, R. C. Genova, B. Girma, E. S. Kissel, A. N. Levy, S. MacCracken, P. R. Mastrandrea, \& L. L. White. (Eds.), Climate Change 2014: Impacts, Adaptation, and Vulnerability. Part B: Regional Aspects. Contribution of Working Group 
II to the Fifth Assessment Report of the Intergovernmental Panel on Climate Change (pp. 1499-1566). Cambridge University Press. Retrieved from https://www.ipcc.ch/site/assets/uploads/2018/02/WGIIAR5Chap27_FINAL.pdf

Martin, T. C., da Rocha, H. R., Joly, C. A., Freitas, H. C., Wanderley, R. L., \& da Silva, J. M. (2019). Fine-scale climate variability in a complex terrain basin using a high-resolution weather station network in southeastern Brazil. International Journal of Climatology ,39 (1), 218-234.

Mauder, M., Cuntz, M., Drue, C., Graf, A., Rebmann, C., Schmid, H. P. \& Steinbrecher, R. (2013). A strategy for quality and uncertainty assessment of long-term eddy-covariance measurements. Agricultural and Forest Meteorology , 169, 122-135. https://doi.org/10.1016/ j.agrformet.2012.09.006

Otto, F. E. L., Haustein, K., Uhe, P., Coelho, C. A. S., Aravequia, J. A., Almeida, W., King, A., Coughlan de Perez, E., Wada, Y., Jan van Oldenborgh, G., Haarsma, R., van Aalst, M., \& Cullen, H. (2016) Factors other than climate change, main drivers of 2014/15 water shortage in southeast Brazil. Bulletin of the American Meteorological Society, 96, S35-S40. https://doi.org/10.1175/BAMS-D-15-00120.1.

Pebesma, E. (2004). Multivariable geostatistics in S: the gstat package.Computers \& Geosciences , 30, 683-691.

Pereira, D. R. (2009). Evapotranspiracao em area de Mata Atlantica na regiao da Serra da Mantiqueira, $M G$. [Doctoral Thesis, Universidade Federal de Lavras, Lavras, MG].

Perez, P. J., Castellvi, M. A. \& Rosel I. R. (1999). Assessment of reliability of Bowen-ratio method for partitioning fluxes.Agricultural and Forest Meteorology, 97, 141-150.

Richards, R. C., Rerolle, J., Aronson, J. Pereira, P. H., Goncalves, H., \& Brancalion, P. H. S. (2015). Governing a pioneer program on payment for watershed services: Stakeholder involvement, legal frameworks and early lessons from the Atlantic forest of Brazil. Ecosystem Services , 16 , 23.

Silva, B. P. C., Silva, M. L. N., Avalos, F. A. P., de Menezes, M. D., \& Curi, N. (2019). Digital soil mapping including additional point sampling in Posses ecosystem services pilot watershed, southeastern Brazil. Scientific Reports , 9(1), 1-123.

Twine, T. E., W. P. Kustas, J. M. Norman, D. R. Cook, P. R. Houser, T. P. Meyers, J. H. Prueger, P. J. Starks, and M. L. Wesely. (2000). Correcting Eddy-Covariance Flux Underestimates over a Grassland.Agricultural and Forest Meteorology , 103(3), 279-300. https://doi.org/10.1016/S0168-1923(00)00123-4.

Vandewiele GL, Xu C-Y, and Win N-L. (1992). Methodology and comparative study of Monthly water balance models in Belgium, China and Burma. Journal of Hydrology 134, 315-347.

Wever, L. A., L. B. Flanagan, and P. J. Carlson. (2002): Seasonal and interannual variation in evapotranspiration, energy balance and surface conductance in a northern temperate grassland. Agricultural and Forest Meteorology. , 112, 31-49.

Wilson, K.B., Baldocchi, D.D. (2000). Seasonal and interanual variability of energy fluxes over a broadleaved temperate deciduous forest in North America. Agricultural and Forest Meteorology. 100, 1-18.

\section{Hosted file}

Chittolina_ET_FiguresTables_vSubmission.docx available at https://authorea.com/users/462962/ articles/558220-hydrological-response-of-a-headwater-catchment-in-southeastern-brazilpart-ii-estimate-of-evapotranspiration-with-micrometeorological-and-water-budget-methods 